\title{
Impact of spinal cord injury on the life roles of women.
}

\author{
M Claire Quigley \\ Thomas Jefferson University
}

Follow this and additional works at: https://jdc.jefferson.edu/otfp

Part of the Occupational Therapy Commons

Let us know how access to this document benefits you

\section{Recommended Citation}

Quigley, M Claire, "Impact of spinal cord injury on the life roles of women." (1995). Department of Occupational Therapy Faculty Papers. Paper 44.

https://jdc.jefferson.edu/otfp/44

This Article is brought to you for free and open access by the Jefferson Digital Commons. The Jefferson Digital Commons is a service of Thomas Jefferson University's Center for Teaching and Learning (CTL). The Commons is a showcase for Jefferson books and journals, peer-reviewed scholarly publications, unique historical collections from the University archives, and teaching tools. The Jefferson Digital Commons allows researchers and interested readers anywhere in the world to learn about and keep up to date with Jefferson scholarship. This article has been accepted for inclusion in Department of Occupational Therapy Faculty Papers by an authorized administrator of the Jefferson Digital Commons. For more information, please contact: JeffersonDigitalCommons@jefferson.edu. 


\section{Impact of Spinal Cord Injury on the Life Roles of Women}

\author{
M. Claire Quigley
}

Key Words: adaptive behavior

This qualitative study was conducted to explore and describe the role experience of five women whose lives were disrupted by a traumatic spinal cord injury and who later retumed to their communities after com-

pleting intensive rebabilitation programs. In-depth interviews and participant observations were used to examine the experiences of these women. The findings exemplify bow the women's use of adaptation and negotiation and the development of a new role as selfadvocate facilitated the reestablishment of their life roles. As the women's occupational roles were redefined, the processes of adaptation and negotiation were evident in three aspects of their lives: daily routines, relationships, and environment. Through their new role of self-advocate, architectural and attitudinal barriers were negotiated and adapted so that roles could be explored. These findings indicate that community reentry involves the ongoing process of negotiation and adaptation of life roles. The use of life bistories during the rehabilitation phase is suggested as a way for therapists to develop meaningful treatment plans that stimulate patients' adaptation process and ultimately enhance community reentry.

M. Claire Quigley, ws, otrl. is Supervisor, Spinal Cord Injury and General Rehabilitation Care Programs, Thomas Jefferson University Hospital, Department of Rehabilitation Medicine, Occupational Therapy Section, 380 Main Building, Philadelphia, PA 19107

This article was accepred for publication November 30,1994
$\mathrm{T}$ his qualitative study explored the occupational roles of five women whose lives had been disrupted because of a traumatic spinal cord injury. Occupational roles serve as a source of identity and a guide for behavior in daily life (Kielhofner, 1985, 1992). They are defined by social norms, demands, and needs, and by the social action and interaction between two or more persons (Biddle \& Thomas, 1966; Cardwell, 1971). Occupational therapists believe that it is through meaningful life roles that a person can explore and master his or her environment in spite of a disability (Reilly, 1969).

The domain of concern for the profession of occupational therapy is to improve role function and the quality of life by facilitating habit and skill acquisition (Kielhofner, 1983). In regard to women with spinal cord injuries, occupational therapy services in rehabilitation programs focus on returning these women to their community to resume old roles and to establish new ones. A review of the literature, however, indicates that little is known about the roles assumed by women with spinal cord injuries who have returned to their community after completing a comprehensive rehabilitation program. With the symbolic interaction perspective of Role Theory (Cardwell, 1971), this study was conducted to explore how women with spinal cord injuries reestablished and engaged in their occupational roles upon returning to their preinjury environments.

\section{Literature Review}

Most of the research on spinal cord injury has focused on medical management, life satisfaction, and depression, and has not been gender specific (Trieschmann, 1988). The little research related to women with spinal cord injury has focused mainly on the physiological aspects of pregnancy and not the overall experience of returning to the community and resuming occupational roles. The lack of information concerning women with spinal cord injury needs to be addressed not only for medical reasons but also to assist in the development of rehabilitation and community programs (Charlifue et al., 1992; Craig, 1990).

On the other hand, there is an extensive and growing body of literature on the changing roles of women without disabilities and the impact that multiple roles have on their physical and mental health. Women of the 1990s are faced not only with occupying the role of mother, spouse, and homemaker, but also with occupying the role of breadwinner. A recent qualitative study by Dyck (1992) supported the idea that women's roles are going through considerable transition. To fulfill the expectations of the conflicting roles of mother and worker, the women in Dyck's study had to redefine motherhood and reconstruct their daily routines and work activities. Dyck's study supported the notion that role content for women "is not static, but is negotiated" (p. 32).

In an earlier study of the effects of multiple roles, 
Verbrugge (1983) examined both men's and women's physical health and concluded that persons with multiple roles tend to have the best health. This finding was due to the effects of each role rather than any special combination of roles. In a second study, Verbrugge (1986) saw the following role factors as links to poor health: "few roles/ activities, and little role responsibility, dissatisfaction with roles/life, very few or very many time constraints and pressures, irregular and short job schedules, no or high family dependency, and very low or high income responsibilities" (p. 73). Verbrugge (1986) also identified role burdens as subjective feelings (e.g., dissatisfaction with roles and life unhappiness). These findings suggest that multiple roles can have a positive effect on health; on the other hand, low quality of roles due to feelings of dissatisfaction and of high time pressure can hinder health status. Women, as compared with men in this study, were at a higher risk of poor health because they identified fewer roles, were less satisfied with their main roles and lives, often had irregular time schedules, and had minimal time constraints and income responsibilities (Verbrugge, 1986). These studies (Verbrugge, 1983, 1986) as well as others (Barnett \& Marshall, 1992) have suggested that women without disabilities who occupy multiple, satisfying roles have the best overall health when compared with women who have few roles and activities.

Today, women who have had recent spinal cord injuries are encouraged by rehabilitation professionals to return to society and to engage in both the traditional and nontraditional roles assumed by their contemporaries. However, persons with spinal cord injuries have been noted to have a difficult time acquiring meaningful roles upon returning to their preinjury communities as a result of environmental, physical, and psychosocial barriers (e.g., social stigma of disability) (Mulcahey, 1992; Trieschman, 1988). Therefore, these persons are in jeopardy of experiencing lower life satisfaction than their contemporaries (Fuhrer, Rintala, Hart, Clearman, \& Young, 1992; Krause, 1992; Yerxa \& Baum, 1986, Yerxa \& Locker, 1990).

Recent studies have supported "that a subject's capacity to sustain meaningful and realistic occupational roles is closely associated with his or her general satisfaction with life" (Branholm \& Fugl-Meyer, 1992, p. 169). Yerxa and Baum (1986) examined life satisfaction and the daily occupations of persons with spinal cord injuries and found a significant association between overall life satisfaction and satisfaction with performance of daily occupations. These findings confirmed that occupational therapists have a vital role in assisting persons with disabilities in participating in meaningful life roles by identifying performance areas in which patients are not satisfied and by exploring and developing new adaptive skills for these performance tasks (Yerxa \& Baum, 1986)

Because this review of the literature indicates that there is a lack of knowledge and understanding of the occupational roles of women who are physically and emotionally challenged by the ramifications of a spinal cord injury, a qualitative study of the life experiences of these women was conducted. The purpose of a qualitative design is to explore, describe, and gain an understanding of the meanings, behaviors, and experiences from the viewpoint of the person under study (Depoy \& Gitlin, 1994; Krefting, 1991).

\section{Method}

Sample

Participants for this study were selected according to the following criteria. They were women; between 25 and 45 years of age; 3 to 5 years postinjury; paraplegic or tetraplegic with an ASIA (America Spinal Cord Injury Association) level of $\mathrm{A}, \mathrm{B}$, or $\mathrm{C}$; residing within a 60 -mile radius of Philadelphia, Pennsylvania; and returned to their community after discharge from a rehabilitation program. The criteria chosen, especially the age and years after injury, were used to enlist a sample of women who were likely to be involved in more than one occupational role. These women's names were retrieved from the database at Thomas Jefferson University Hospital, Regional Spinal Cord Injury Center of Delaware Valley, Philadelphia, Pennsylvania. From this database, a list of 20 women, nine of whom met study criteria, was generated. When contacted by telephone and told the purpose of this study, five of the nine agreed to participate and were enrolled in the study. See Table 1 for the demographics of the participants.

\section{Collection and Analysis of Data}

Two methods of data collection were used for this study: intensive interviews and participant observation (DePoy \& Gitlin, 1994). In addition, extensive field notes were maintained throughout the study.

As the primary researcher, I spent a total of 6 to $10 \mathrm{hr}$ with each participant. During this time, I conducted an indepth interview and actively observed each participant in her own environment which included home, workplace, stores, a Gir] Scout meeting, schools, an airport, automobiles, and athletic events. The interview questions were semistructured and included select probes from the

\section{Table 1}

Demographics of Participants

\begin{tabular}{lccccc}
\hline Participant & $\mathrm{I}$ & 2 & 3 & 4 & 5 \\
\hline Age & 36 & 27 & 36 & 29 & 27 \\
Type of injury & $\mathrm{P}$ & $\mathrm{T}$ & $\mathrm{P}$ & $\mathrm{P}$ & $\mathrm{P}$ \\
Years after injury & 4.4 & 4.8 & 3.1 & 4.5 & 3.1 \\
Mantal status & $\mathrm{S}$ & $\mathrm{S}$ & $\mathrm{M}$ & $\mathrm{S}$ & $\mathrm{S}$ \\
Children & 3 & 0 & 3 & 0 & 0 \\
Emploved & No & No & Yes & Yes & Yes \\
Student & Yes & Ycs & No & No & No \\
\hline
\end{tabular}

Note. $\mathrm{P}=$ paraplegia $\mathrm{T}=$ tetraplegia, $\mathrm{S}=$ single, $\mathrm{M}=$ marsied. 
five domains of the qualitative dimension of the Occupational Performance History Interviews (Kielhofner, Henry, \& Walens, 1989). The domains included: organization of daily living routines; life roles; interests, values, and goals; perception of abilities and assumption of responsibility; and environmental influences. Each interview was audiotaped and later transcribed verbatim. Field notes were also kept to document my behavior and experience in the field and to reflect upon my own thoughts and feelings about each participant observation.

Ongoing analysis guided the data-gathering process, during which questions were refined and limits were set as to who and what was to be explored (DePoy \& Gitlin, 1994). The first formal analysis involved multiple readings of the transcripts and field notes. Statements were identified that referred to occupational roles and answered the broad question: What were the roles these women engaged in after returning to their community with a spinal cord injury? On the basis of responses that related to these women's occupational roles (past, present, and future), 26 categories were identified that were either common or unique to each participant's experience. The relationships of these 26 categories to each other were then analyzed, and salient themes developed portraying the participants' experience in returning to their community with a spinal cord injury.

\section{Credibility}

Three methods, triangulation of data, field notes, and peer debriefing, were used to enhance the trustworthiness of the data collection and analysis. In-depth interviews, participant observation, and field notes were used to cross-check and verify the emerging interpretations and to increase the credibility of the findings (DePoy \& Gitlin, 1994). For each participant, observation field notes were kept so that I could become aware of my own biases as the primary researcher. These field notes reflected on my thoughts, feelings, and behavior regarding each interview and participant observation. Finally, peer debriefing, which involved two university professors with experience in qualitative research (one with expertise in occupational therapy and the other with expertise in sociology), was used to enhance the accuracy of this study. Each professor independently read the transcripts and field notes and confirmed or questioned categories and emerging themes. This peer review occurred multiple times during the analytic process and provided me with the opportunity to reflect on, compare, and explore other possible interpretations (Depoy \& Gitlin, 1994). Consensus occurred regarding the emerging categories and themes.

\section{Findings}

There were three major findings in this study. The first finding indicated that in spite of the ramifications of a spinal cord injury, the participants occupied multiple and various roles such as worker, lover, athlete, student, volunteer, family member, and employer. The occupational roles identified by the five participants were not limited to traditional domestic roles.

The second finding was the consistent use of processes and skills of negotiation and adaptation by all the participants to explore and resume their occupational roles. Upon returning to their communities, the participants not only had to redefine their occupational roles but, to engage in these roles, they also had to adapt to their surroundings and to societal expectations. Their daily routines, relationships, and environment were all affected. Reconciliation of problems in these areas were dependent on their personality traits, level of spinal cord injury, and availability of social support.

The third and critical finding was that all participants assumed and developed a new role upon returning to their communities -- that of self-advocate. For this new role, the participants negotiated and adapted to many architectural and attitudinal barriers that initially blocked them from resuming and exploring desired occupational roles.

In discussing the findings, I will first focus on the role experience of the participants in their community and the themes of adaptation and negotiation within the following areas: daily routines, relationships, and environment. I will then address the role of self-advocate and its significance and relationship to the themes of adaptation and negotiation.

\section{Daily Routines}

To be able to engage in occupational roles, all participants described modifications to their daily routines. Each described herself and her activities as more organized and less spontaneous when compared with her life-style before injury. The following quote highlights how one participant adapted her routine because of her physical needs. It demonstrates the constant comparison of a person's past self to a person's present self as a salient thinking process to redefine a new self.

Before my accident I was spontaneous too, but I could stay up
later and I could read at night after everybody went co bed. I could
stay up and sew to 12 o'clock or 1 o'clock or whatever. Now that
I've had this accident, my energy level is gone. By 11 o'clock I'm
ready for bed, so I can't stay up like I used to.

Along with adjusting daily routines to accommodate the physical ramifications of spinal cord injury, each participant also had to reorganize her role content. Physical abilities were factors when deciding which roles were to be resumed or how to juggle the multiple roles of homemaker, mother, worker, student, and others. The following quote illustrates how one participant attempted to renegotiate her previous routines and roles, both as 
worker and student, to adjust to her present strength and balance:

If I was working I wouldn't be able to go to school. Before, I would have tried to work and try to take classes. I wouldn't try that now. It's too much, too much trying to get around. I can't get the wheelchair in and out of the car yet, that's the one thing that's holding me up . my balance, I can't it's, it's kind of hard to, I get the front in, but I don't have enough strength or something to pull the back wheels up.

Again, physical needs resulting from spinal cord injury were the impetus for accommodations to preinjury routines. All participants had to conform daily routines to a structured bowel and bladder program and feminine hygiene issues. This daily habit was described as both "frustrating" and "time consuming." The following quote demonstrates how a bowel program affected a typical day for one participant: "Nobody wants to have a bathroom thing in the morning that's going to take them 45 minutes to an hour. I mean you can think of better things you can be doing with your time, but it's a necessity." As illustrated in the following quote, this same participant, in spite of the aggravations over her bowel program, arranged her schedule to accommodate her role as a friend.

I wish there was a way to shotten my routine in the morning. But the only way to make it shorter is to do my bowel program at night. If I did, it would save me an hour in the morning. But to me, I don't ever know what l'm doing at night. A friend of mine could call me up and say, "You want to come over to the house or go out to dinner?" I enjoy that, like go out to dinner with my friends. Like I said, I don't want to schedule my life. At least if you get it done in the morning, its done so the day is yours

Through trial and error, the participants were able to adapt their previous daily routines to fit their present time constraints and physical abilities. Their awareness of the demands resulting from their spinal cord injury allowed them to establish and adjust daily routines that enhanced their ability to engage in and juggle multiple roles

\section{Relationships}

Negotiation of relationships, both old and new, was apparent in all the transcripts and field observations. For some, such roles as mother, friend, and worker had to be redefined to meet society's expectations of that role. An example is the role of mother. The participants who occupied this role before sustaining a spinal cord injury wished to maintain their old self as "mom" - as the one their children could rely on. They did not wish to be viewed by their children as "needy" or "dependent" because of their physical limitations. These women made role adjustments by shifting role obligations between themselves, their husbands, and their children in order to prevent role insufficiency. In the following comment, one participant shares how child care and the act of disciplining was negotiated with her husband and children.

It has changed in several ways. I still do a lot for my kids, bur they have to do a lot for themselves now. Like for instance if they're sick, they know if they throw up on the floor they clean it up; I don't clean it up. So they know they better get that bowl or pan to throw up in, otherwise they got the mess. They've had to take more responsibility. I had to come up with different disciplines and stuff like that. At times it's very difficult in that my son knows he can get away with things. He knows that I can't always see him. He knows I can't chase him across the yard. and he also knows when he gets back to this house he's going to be in deep trouble. So its like a catch-22. I had to hand some of the discipline over to my husband because 1 just lose patience due to the fact that I can't correct. I have never been a physical corrector but I can't physically make sure my son goes to his room. I can send him to his room, but that doesn't mean he always goes to his room, and it's like I can't force him. I can't bodily move him to get him into his room.

Motherhood was also a concern for the participants who did not occupy that occupational role before their injury. Their concern focused on the limitations posed by their physical condition and their ability to care for a child. The following comment highlights the fears of one participant and the adaptations she had already begun to calculate.

I'm scared. I'm nervous about having kids. I wonder how I would manage all that. Plus I don't have the balance. T've had people put babies on my lap and, because of the balance. I'm really nervous about holding very tiny infants. And I know that's somerhing I'll have to work out. I might even have to have help when I fitst have a kid until the kid gets a little bit older, where you don't have to be so careful abouk holding, supporting their head or something like that.

Not all relationships were negotiable. Individual attitudes toward physical disabilities made it difficult for these women to develop new relationships and reestablish old ones. In response to the question, "Are there people making things difficult for you?" one participant demonstrated the various ways she encountered attitudinal barriers while participating in her claily activities.

Mm-hnm. yup! The human beings that call themselves human beings that are not considerate or careful of anybody. The ones who park in handicapped parking spots and they know that they re not allowed. The ones who park in handicapped people [reserved spots] where you can't get out of the van. "The people that treat me like I'm mentally incompetent. Some friends that don't know how to handle this and handle it prong. Unfortunately for them, I wish I could reach out and shake them and say. "It's okay, don't wory so much about how you'te feeling."

Attitudinal barriers were also obstacles for the participants when returning to employment status. Unfortunately, not all employers were willing to accommodate these women because they were "disabled." One participant expressed:

'This was the furst weck I was there [at work] and he hadn't cven seen my ability to teach yet. and he said to me. "I have to tell you

if I was in charge of hiring and it was a docision to hire somcone who was not in a wheelchair and you who's in a wheelchair, even if you were the more qualified person, I would hire the other person because I wouldn t have to make any special arrangements for them. And I just think you are a betler teacher if you can stand at the blackboard to ieach."

Upon returning to their communities, the boundaries of each relationship, wherher they were old or new, formal or informal, had to be redefined and adapted to by each participant. The participants' level of comfort with 
their physical abilities appeared to assist them in negotiating the expectations of each role.

\section{Environment}

The environment both hindered and helped these participants in carrying out their occupational roles. Physical adaptations, such as an adapted van or car, ramps, an elevator in the home, or an overhead projector at work, assisted these women in homemaking, shopping, parenting, working, traveling, and other activities. On the other hand, the environment also had many barriers. Frequently, throughout the course of a day, these participants unexpectedly had to negotiate their roles and routines or adapt a special technique because of environmental barriers. Inaccessibility and ways in which the environment had to be negotiated was a common theme in all the transcripts. For example, the participants often described bathrooms as being inaccessible because the stalls were too small, the doors to the stalls opened inward, and the toilets were too low. One participant stated:

I'm not satisfied with having to catheterize myself. . . It's really tough for a woman. When you go into public rest rooms and they claim to be accessible and I can't even get the wheelchair through the stall. I'm not satisfied with that at all.

While attending a weekend conference for work, one participant had to adapt her bowel and bladder care because the door to the bathroom was too narrow. She commented:

I had to stop taking my laxative the second I got there so I would not.. have a BM while I was there, and I had to catheterize myself in the bed to go to the bathroom every time I had to go to the bathroom for the entire weekend.

This participant's ability to negotiate this architectural barrier enabled her to fulfill the expectations of her worker role.

These participants shared many experiences in which they had to adapt to architectural barriers in order to participate in their occupational roles. Their skills and abilities to adjust and negotiate these barriers in a moment's notice were augmented and refined by the multiple barriers they encountered and experienced during a typical day.

\section{Self-Advocacy}

Architectural and attitudinal barriers were a burden to all five participants. They often impeded role exploration and resumption. Through a new role as self-advocate, the participants took an active part in negotiating these obstacles in order to make their lives, and the lives of orhers with disabilities, easier. They spoke informally and formally to persons of all ages about disability and barriers. Some wrote letters or openly complained about the obstacles they encountered. The excerpt that follows typifies the self-advocacy role and illustrates examples of how one woman negotiated the barriers she faced when participating in many of her roles.

No, I complain. No, I complain . normally vocally. Now with the Lancaster deal [hotel], I wrote a letter Now I understand they have written me a letrer back and said that because of my stay they have changed and modified some of their rooms.

I would like to reach out to more people, to have them understand that we're just normal people, that we're people too. You know, I don't like being treated like I'm not only physically handicapped but I'm mentally handicapped. I don't like being treated like I'm a nonentity. . I would like to be able to speak out more, especially with children, even with grown-ups, about dealing with a handicap. How you can overcome adycrsity. How you can make your life better.

They asked me to speak to a group of employers about hiring a handicapped person, so I spoke to about 60 people, how easy it is to hire us, how we're reliable, how you don't catch us standing in doorways talking because we can't get out of the way fast enough!

I've talked scveral times to several different groups. Like last year I taiked to different groups in my son's school. .. What I try to do is relate it or correspond it with something they're studying.

This new role of self-advocate enabled these women to negotiate, adapt, and pursue old and new roles. They were also able to educate the public about disabilities and barriers.

\section{Discussion}

The findings of this study reveal that community reentry for women with spinal cord injuries involves the ongoing process of negotiation and adaptation of life roles (past, present, and future) to accommodate to the wide array of challenges they encounter in their communities. In spite of the number of years after injury, the five participants in this sample still actively worked to reconstruct their lives while attempting to redefine and reorganize their role content and behaviors. They accomplished this feat by combining, amending, and contrasting their past lifestyles into their present and anticipatory roles. Bateson (1989) stated that "the past empowers the present, and the groping footsteps leading to this present, mark the pathways to the future" (p. 34).

In recomposing their lives, the women drew from their previous experiences in managing the many role demands before their spinal cord injury. Adaptation for them required that they reexamine their relationships and sense of self (Swanson, Cronin-Stubbs, \& Sheldon, 1989). This reexamination enhanced their ability to reestablish their occupational roles, to become selfadvocates, and to plan for their future.

The role experiences of the participants support the concept that women's roles are changing even in the world of disability. In general, women with disabilities are "perceived as unable to fulfill traditional roles" (Crist, 1991, p. 39). However, as demonstrated by these participants, women with spinal cord injuries are not helpless, nonproductive beings. They have the ability and are capable of occupying and engaging in many diverse roles.

A weakness of this study is that member checking 
(Depoy \& Gitlin, 1994) between the participants and me did not occur. This strategy would have ensured that the findings reflected the participants' experiences and would have enhanced the credibility of this study (Krefting, 1991)

\section{Implications for Practice and Research}

Adaptation is a continual, satisfactory adjustment that moves persons beyond survival needs (Crist, 1991). The adaptive process has four basic elements:

1) an active response; 2) evoked by the specific environmental demands of needs, tasks, and goals; 3 ) efficiently organized below the level of consciousness, with conscious attention being directed to objects or tasks; 4) self-reinforcing, with each successful adaptation serving as a stimulus for tackling the next more complex environmental challenge (King, 1978).

The goal of occupational therapy is to guide and facilitate this adaptive process to enhance independence and actualize potential regardless of disability (King, 1978).

Occupational therapists recognize that persons experience role dysfunction when they "cannot perform roles to satisfaction, either because of deficits and skills due to disease or disability, the conflicting demands of multiple roles, or because of unclear role expectations" (Christiansen, 1991, p. 30). To sufficiently assist women with disabilities in reestablishing meaningful roles, occupational therapists must first recognize the "demographic trends and emerging life styles" (Brady, 1991, p. 84) of women in the late twentieth century. Women are not only expected to be the primary homemaker but also to occupy a full-time job or have a professional career. With an awareness of today's role expectations for able-bodied women and an understanding of the processes of adaptation and negotiation, occupational therapists can assist women with spinal cord injuries in exploring life roles before discharge from a rehabilitation setting.

On the basis of the findings of this study, I suggest that during the rehabilitation phase, life histories be used to better understand a person's life-style, personal goals, and values in order to design meaningful treatment plans that stimulate the adaptive process in therapy (Kielhofner, 1985; Lynch \& Bridle, 1993). These activities would facilitate entry into new roles, such as selfadvocate, as well as reestablishment of old ones. I recommend the following activities during the rehabilitation phase to promote community reentry of women with spinal cord injuries: opportunities to practice, adapt, and negotiate old and developing roles (both traditional and nontraditional roles); opportunities for exploration and repetition of coping techniques; role play of situational conflicts that promote self-advocacy; and introductions to other women who have incurred a spinal cord injury and have returned to their community, as role models and for a resource network.

In addition, women without disabilities should be further studied to create health promotion programs to prevent possible illnesses (Hall, Stevens, \& Meleis, 1992). Studies in this area and on women with disabilities can provide insight on coping strategies that can be used to help negotiate and adapt to the changing demands and expectations of their environment. This research is vital for the future well-being of women. By gaining a richer understanding of the lives of women in today's society, occupational therapists can create innovative programs to assist in the increasingly demanding tasks of women's roles and to foster role balance that is consistent with a healthy life-style.

\section{Acknowledgments}

I thank my graduate committee: Laura N. Gitlin, PhD,, Jerry Johnson, EcID. OTR/L. FAOTA, and Ruth Schemm, EdD, OTRA, FAOTA, as well as the Department of Occupational Therapy at Thomas Jefferson University Hospital for their support and guidance throughout the course of this project. I also thank the five women who participated in this study and allowed me to explore their lives.

This project was completed in partial fulfillment of the master's of science degree in Occupational Therapy at Thomas Jefferson University, Philadelphia, Pennsylvania.

\section{References}

Barnett, R., \& Marshall, N. (1992). Worker and mother roles, spillover effects, and psychological distress. Women and Health, 18,940 Monthly.

Bateson, M. (1989), Composing a life. New York: Atlantic

Biddle, B. J., \& Thomas, E. J. (Eds.). (1966). Role theory: Concepts and research. Huntington, NY: Krieger.

Brady, C. (1991). Occupational therapy practice: Practice dilemma. In P. Dougherty \& M. V Radomski (Eds.), Occupational therapy practice (pp. 82-85). Gaithersburg, MD: Aspen.

Branholm, I. \& Fugl-Meyer, A. (1992). Occupational role preferences and life satisfaction. Occupational Therapy Journal of Research, 12, 159-171.

Cardwell, J. (1971). Social psychology: A symbolic interactionist perspective. Philadelphia: F. A. Davis.

Charlifue, S., Gerhart, K., Menter, R., Whiteneck, G., Scott, M., \& Manley, M. (1992). Sexual issues of women with spinal cord injuries. Paraplegia, 30, 192-199.

Christiansen, C. (1991). Occupational therapy: Intervencion for life performance. In C. Christiansen \& C. Baum (Eds.), Occupational therapy: Overcoming buman performance deficits (p. 443). Thorofare, NJ: Slack.

Craig, D. (1990). The adaptation of pregnancy of spinal cord injured women. Rebabilitation Nursing, 15, 6-9.

Crist, P. (1991). Motherhood revisited: Balancing parenthood and disability. In P. Dougherty \& M. V. Radomski (Eds.), Occupational therapy practice (pp. 34-47). Gaithersburg, MD: Aspen.

DePoy, E., \& Gitlin, L. (1994). Introduction to research: Multiple strategies for bealth and buman services. Philadelphia: Mosby.

Dyck, I. (1992). The daily routines of mothers with young children: Using a sociopolitical model in research. Occupational Therapy Joumal of Research, 12, 16-34.

Fuhrer, M., Rintala, D., Hart, K., Clearman, R., \& Young, M. (1992). Relationship of life satisfaction to impairment, disability, and handicap among persons with spinal cord injury living in 
the community. Archives of Pbysical Medicine E Rebabilitation, 73, 552-557

Hall, J., Stevens, P., \& Meleis, A. (1992). Developing the construct of role integration: A narrative analysis of women clerical workers' daily lives. Research in Nursing and Health, $15,447-457$

Kielhofner, G. (1983). Health through occupation: Theory and practice in occupational therapy. Philadelphia: F. A. Davis.

Kielhofner, G. (1985). A model of buman occupation: Theory and application. Baltimore: Williams \& Wilkins.

Kielhofner, G. (1992). Conceptual foundations of occupational therapy. Philadelphia: F. A. Davis.

Kielhofner, G., Henry, A., \& Walens, D. (1989). A user's guide to the occupational performance bistory interview. Rockville, MD: American Occupational Therapy Association.

King; L. J. (1978). Toward a science of adaptive responses1978 Elcanor Clarke Slagle Jecture. American Joumal of Occupational Therapy, 32, 429-437.

Krause, J. (1992). Adjustment to life after spinal cord injury: A comparison among three participant groups based on employment status. Rehabilitation Counseling Bulletin, 35, 218 229.

Krefting, L. (1991). Rigor in qualitative research: The assessment of trustworthiness. American Joumal of Occupation- al Therapy, 45, 214-222.

Lynch, K. \& Bridle, M. (1993). Construct validity of the occupational performance history interview. Occupational Therapy Joumal of Research, 13, 231-240.

Mulcahey, M. J. (1992). Returning to school after a spinal cord injury: Perspective from four adolescents. American Journal of Occupational Therapy, 46, 305-312.

Reilly, M. (1969). The educational process. American Journal of Occupational Therapy, 23, 299-307.

Swanson, B., Cronin-Stubbs, D., \& Sheldon, J. (1989). The impact of psychosocial factors on adapting to physical disability: A review of the literature. Rehabilitation Nursing, 14, 64-68.

Trieschmann, R. (1988). Spinal cord injuries: Psychological, social, and vocational rehabilitation. New York: Demos.

Verbrugge, L. M. (1983). Multiple roles and physical health of women and men. Joumal of Health and Social Bebavior, 24, $16-30$.

Verbrugge, L. M. (1986). Role burdens and physical health of women and men. Women and Health, 11, 47-77.

Yerxa, E., \& Baum, S. (1986). Engagement in daily occupation and life satisfaction among people with spinal cord injuries. Occupational Therapy Joumal of Research, 6, 271-283.

Yerxa, E., \& Locker, S. B. (1990). Quality of time use by adults with spinal cord injuries. American Joumal of Occupational Therapy, 44, 318-326.

\title{
Work in Progress:
}

\section{Occupational Therapy in Work Programs}

\author{
Edited by Sarah Hertfelder, MEd, MOT, OTR, \\ and Carol Gwin, OTR
}

$W^{\text {ork in Progress further defines the profession's role in work programs. It assists occupational }}$ $W$ therapists in helping people with disabilities make the transition into gainful employmentwhether they are entering the work force for the first time or returning to work following a traumatic experience. Explores current topics such as ergonomics, work hardening, transitional employment, and prevention. 291 Pages, 1989.

Contents include:

- Department of Labor References and Job Analysis

- Work Hardening - Transition from School to Adult Life

- Overview of Supported Employment - Ergonomics and the Occupational Therapist, and more! Order \# 1720 \$31.00 AOTA member \$40.00 nonmember

To order, call 1-800-SAY-AOTA (members), 301-652-2682 (nonmembers), or 1-800-377-8555 (TDD customers). Shipping and handling additional. 